\title{
O ENTRE-LUGAR DO DESENHO CONTEMPORÂNEO: \\ Processo-fatura
}

Vanessa Bortucan

\section{RESUMO}

O texto apresenta problematizações a partir da temática do desenho, com a finalidade de trazer para debate este como fragmento-ideia e as implicações artísticas desta característica contemporânea, onde tudo pode ser legitimado pela retórica prolixa do discurso estruturado em moldes institucionais que corroboram com incertezas, enaltecendo os excessos e fragilidades no âmbito das artes.

Palavras Chave

Desenho, arte, excesso, discurso.

\begin{abstract}
The text presents problematizations from the drawing theme in order to bring to debate drawing as fragment-idea and the implications of this feature in contemporary art where everything can be legitimized by a prolix rhetoric of structured discourse in contributive way stoun certain ties, extolling the excesses and fragilities within the arts.
\end{abstract}

Key words

Drawing, art, excess, discourse.

Durante a explanação para o evento Estados de In[certeza] realizado no museu da Escola Catarinense em Florianópolis sobre a temática de minha pesquisa, apresentei questionamentos que há algum tempo germinam em minha mente sem respostas. Como relatado, o início das problematizações surgiram com a aproximação à artista Jandira Lorenz e o estudo aprofundado sobre seu processo criativo. Foi o desenho, mote primeiro da pesquisa, que proporcionou uma 
investigação sobre o acaso, sua relação com o gesto, o processo da fatura, e como o olhar ao passado está imerso e diluído no nascimento da obra.

Todas as conexões com os artistas do passado em prol de uma busca infindável e indefinível veio em minha direção, de modo a comparar às ações e reflexões dos artistas do presente. Muitas dúvidas e questionamentos surgiram quanto mais eu percorria os caminhos dos congressos de arte, dos museus de arte contemporânea, bienais e publicações de artistas, todos em defesa de uma maior democratização da arte, de uma arte contemporânea que supostamente corrobora com a abertura de caminhos mais inerentes à filosofia (sem desconsiderar a importância desta no pensar artístico) do que da própria arte. Esta nova visão pluralista propagadora de uma democracia cultural se coloca perante um mundo "diferente" que não mais tem referências em categorias do passado, e por isso, algumas perguntas são consideradas desnecessárias e retiradas do contexto.

Não afirmo que a pluralidade de estilos seja danosa ${ }^{1}$, mas o cuidado que separa a tênue linha das armadilhas de discursos vendáveis é necessário. Neste sentido, ao se manter escondida a superficialidade de afirmações ao desconsiderar a possibilidade de pensar as exceções em favor de uma diversidade prejudicial pela inexistência crítica e, sobretudo à falta de critérios e parâmetros sobre a especificidade da arte, corre-se o risco de promiscuir a seriedade daqueles que estão efetivamente interessados no estudo da arte eque acreditam em sua potência como linguagem. De igual forma, comprometem todos os artistas que procuraram incansavelmente contribuir com uma produção muito bem elaborada, intrínseca àquilo que está diretamente relacionado à percepção sensível, que o conecta com algo que foge e perpassa a razão que a fala tenta instituir.

Ao olhar para o hoje adentrando no pensamento da maioria dos pesquisadores do desenho, entendo (a partir do que entendem na atualidade) o processo de desenhar como fatura. Assim, estabeleço conexões entre o tempo contemporâneo, nosso tempo de excessos, onde se habitam fragmentações. $E$ a partir destas fragmentações penso o desenho como fragmento-ideia de modo a

\footnotetext{
${ }^{1}$ Mas que também pode ser, pois toda verdade carrega em si o seu contrário. Generalizar demais pode fazer com que tudo se perca de vista.
} 
ampliar possibilidades de reflexões a partir do que existe e habita o mundo contemporâneo.

A síntese da pesquisa inicial abarca o campo de estudo da teoria, da história e da crítica de arte, pois objetiva-se construir um pensamento sobre o processo artístico do desenho contemporâneo, criando conexões com a história da arte, de modo a friccionar o hoje com o ontem, propondo reflexões sob um viés crítico. Como são demasiadas as incertezas, disponho em forma de perguntas o levantamento das problemáticas que acredito permear o contexto artístico atual.

1. Como se apresenta o desenho contemporâneo entre essas multiplicidades de formas de fazer em relação ao passado? Antes como era visto o processo e agora como é?

2. O que difere o desenho-processo como arte e não como ferramenta de estudo, esboço de uma ideia?

3. O que faz do desenho- processo (fragmentos-ideia ${ }^{2}$ ) arte agora?

4. Há perda da experiência e perpetuação do efêmero no momento em que o caráter de estudo do processo é abolido?

5. A experiência é substituída pelo discurso legitimador (até mesmo fora da intencionalidade artística)? E quem legitima?

Se a arte reflete nosso tempo, podemos partir deste reflexo para pensarmos na expansão e nas multiplicidades que surgem com o contemporâneo no campo da linguagem do desenho. No contemporâneo se ampliam as novas formas de pensar o desenho, principalmente como registro, processo (como arte e não como processo concebido até certo momento histórico). O desenho agora também participa da captação da fragmentação e das novas possibilidades de ser arte que a intencionalidade e o gesto do artista possibilitaram (a partir de Duchamp, com a deflagração da ideia de arte conceitual).

O que difere o desenho-processo como arte e não como ferramenta (aliada à técnica) de estudo, esboço de uma ideia? Uma das possibilidades de pensar essa ampliação é o desenho como pensamento, que abarca as formas de ser desenho, o

\footnotetext{
${ }^{2}$ Como eu os denomino. Percurso das ideias que se tornam fragmentos-ideia.
} 
desenho-processo.

O desenho como processo é o desenho que pode surgir sem qualquer intencionalidade do artista, é o desenho que não exclui o acaso, é o rascunho de uma ideia. E o que faz dele arte agora? A intencionalidade do artista no momento em que ele junta esses fragmentos de ideias e ao juntar esses fragmentos-ideia através de um caderno, de coleções, o artista está fazendo arte (arte como fatura), mesmo que ele não chegue a nenhum lugar resultante ${ }^{3}$ (desenho como resíduo)? Quando o artista coleta fragmentos das ideias, os coleciona e os junta com intencionalidade, ele está dando vida a uma nova forma de arte (entendida e legitimada no contemporâneo, como a obra em si)?

O que pretendo problematizar é o cuidado necessário para que o colecionismo contemporâneo não elimine a potência da obra no momento em que essa junção/coleção cria narratividade - não me refiro a uma narratividade intrínseca à linguagem expressiva, que seria a da ordem da potência.

\section{O que seria essa narratividade perigosa?}

1. Quando o desenho-processo a partir do colecionismo, tenta criar narrativas, de modo a preencher o impreenchível da arte. É quando o desenho-processo peca pelo excesso ${ }^{4}$ e pela falta de fascínio ${ }^{5}$ que poderia exercer sobre o espectador quando não segura o enigma ${ }^{6}$ e perde a potência como obra ou como processo-obra ${ }^{7}$ (se contrapondo a ideia de processo como um nem

\footnotetext{
${ }^{3}$ Como em relação ao passado - conceito de grande obra.

${ }^{4}$ BAUDRILLARD, Jean. A Arte da Desaparição. Rio de Janeiro: Editora UFRJ, 1997.

${ }^{5} \mathrm{O}$ que inaugura um poder de ilusão.

${ }^{6}$ Segundo Maurice Blanchot: desviar do destino, não se submeter a linguagem, que me coloca diante do neutro (do obscuro, diante da experiência do improvável, do inominável, do que não posso dizer; grande recusa diante da suspensão da experiência). BLANCHOT, Maurice. O espaço literário. Rio de Janeiro:Rocco, 2011.

${ }^{7}$ Obra como neutro de Blanchot ourastro de Derrida. DERRIDA, Jacques. Pensar em não ver. Florianópolis:
} 
resíduo ${ }^{8}$, que não chega ao fascínio porque não consegue nem chegar a resíduo).

2. Quando o discurso faz a obra. É quando a palavra quer fixar a presença (significado). Ou seja, quando o público (críticos, historiadores, outros artistas) de modo a justificar a obra, criam um trabalho mais potente muitas vezes do que a própria obra - Arte x Discurso. Neste território da arte versus discurso, a experiência é substituída pelo discurso legitimador (até mesmo fora da intencionalidade artística), desconsiderando a imagem como potência, extinguindo-se a relação neutra, a da experiência. O que promove a destruição da potência como algo que pode vir a ser, não sendo, nem possibilidade nem impossibilidade, mas o improvável.

Se as coisas existem e se relacionam, porque precisamos crer em dependências absolutas entre linguagens distintas? Agora parece que a arte precisa do discurso, pois a imagem já não é rastro, nem vestígio ${ }^{9}$ e sim um nem resíduo ${ }^{10}$. São literalmente imagens que não deixam rastros. É a iconoclastia moderna ${ }^{11}$, que consiste em fabricar uma profusão de imagens em que não há nada para ver, pelo excesso de realidade. De tão imanente - desnecessário. No contemporâneo nada pode se perder, qualquer esboço e qualquer ideia precisa ser guardado ou apresentado como arte, o que me faz pensar na perda da experiência, de modo que o conhecimento vira discurso e desconsidera-sea participação significativa do ser arte em favor do discurso. Discurso que media a experiência, infundindo, portanto, a linguagem como violência, colocando seu referente ao que não se pode abarcar ${ }^{12}$.

\footnotetext{
Editora da UFSC, 2012.

${ }^{8}$ Como eu os denomino.

${ }^{9}$ LEVINAS, Emmanuel. A realidade e sua sombra. Madrid: Trotta, 1994.

${ }^{10}$ Denomino como nem resíduo o momento em que a imagem é tratada como resíduo antes mesmo de chegar ao domínio do fascínio.

${ }^{11}$ BAUDRILLARD, op. cit., 1997.

${ }^{12}$ Deixando de ser sombra enquanto apanhada. Descartando a realidade como sombra.
} 
Há uma problemática visível e crescente do contemporâneo que é querer dar conta da multiplicidade de fragmentos. É como se tivéssemos que acreditar queo excesso diz algo pela quantidade, como se os milhares de objetos, milhares de imagens dispostas nas coleções expostas como arte fossem arte somente porque são coleções do artista. Parece que o mundo explodiu em milhões de pequenas partículas e agora é como se essas partículas tivessem que ser juntadas uma a uma, mesmo que isso não seja possível e necessário. Parece haver uma angústia por uma necessidade de não deixar nada mais escapar aos olhos, (tudo precisa ser considerado, até o mais efêmero, qualquer registro etc.). Por isso que no contemporâneo se criam excessos? É como se esses excessos pudessem suprir a falta de profundidade, como se pudessem preencher as lacunas intrínsecas da arte. Há uma necessidade do artista de dar ao mundo (em forma de arte) o próprio mundo. É como se a arte fosse agora o espelho desse mundo onde tudo é excesso e pouca profundidade.

Tudo ao se tornar confuso, incide no distanciamento dessa arte pseudodemocrática em relação ao seu público, que ou acredita precisar do discurso ou não acredita na Arte. Após tantas problemáticas elencadas e revistas nesta sistematização a partir do estudo sobre a mudança do processo de pensarmos o desenho, alterando a relação deste com os ensinamentos e referências passadas, deparei-me com o respaldo de Giorgio Agamben ${ }^{13}$, quando ele discorre sobre a crise na relação com o passado. O autor numa entrevista diz que "oúnico lugar em que o passado pode viver é o presente, e se o presente não sente mais o próprio passado como vivo, o museu e a arte, se tornam lugares problemáticos" e os museus, portanto podem se tornar templos absurdos.

Ao retomar meu pensamento em relação ao gesto de Duchamp, será que podemos afirmar queumready-made possa se fazer presença como obra? Agambenesclarece que:

(...) certamente ele não queria produzir uma obra de arte, mas desobstruir o caminhar da arte, fechada entre o museu e a mercantilização. (...) o que de

\footnotetext{
${ }^{13}$ AGAMBEN, Giorgio. Deus não morreu, ele se tornou dinheiro. Entrevista disponível em: < http://www.pragmatismopolitico.com.br/2013/06/deus-nao-morreu-ele-se-tornou-dinheiro.html>. Acesso em jun. 2013.
} 
fato aconteceu é que um conluio, infelizmente ainda ativo, de hábeis especuladores e de "vivos" transformou o ready-made em obra de arte. E a chamada arte contemporânea nada mais faz do que repetir o gesto de Duchamp, enchendo com não-obras e performances em museus, que são meros organismos do mercado, destinados a acelerar a circulação de mercadorias, que, assim como o dinheiro, já alcançaram o estado de liquidez e querem ainda valer como obras (AGAMBEN, 2013).

E o que o desenho tem a ver com tudo isso? Respondo com uma frase de Hans Belting ${ }^{14}$, ao dizer que agora a experiência estética parece um problema que necessita de esclarecimento, e o discurso acadêmico quer convencer o mundo não acadêmico (leigos) que este depende dele, oferecendo as fórmulas adequadas para conferir validade a uma cultura científica mediante teses que satisfazemsomente a si mesmo e seus interesses, porque é neste espaço onde tudo parece possível que "muitos ganham o pão com a mudança daquele discurso que os sustenta ${ }^{15 " .}$

Aqui estão esboçadas minhas palavras construídas a partir das leituras de autores diversos. São somente reflexões sobre um terreno bastante movediço, mas que segue em busca de possibilidades de encontrar mais perguntas ao invés de respostas.Respostas que me escapam cotidianamente, em um fecundo estado de incerteza.

\footnotetext{
${ }^{14}$ BELTING, Hans. O fim da história da arte. São Paulo: $1^{\text {a }}$ edição Cosac Naif Portátil, 2012.

${ }^{15}$ Idem, Ibidem, p. 26.
} 